\title{
INFLUENCE OF SURFACTANT STRUCTURE ON PHYSICAL STABILITY AND PHYSICO- CHEMICAL PROPERTIES OF INSECTICIDE EMULSIONS
}

\author{
SUMAIYAH MEGAT NABIL MOHSIN*; ISMAIL AB RAMAN*; ZAFARIZAL ALDRIN \\ AZIZUL HASAN* and ZAINAB IDRIS*
}

\begin{abstract}
A stable oil-in-water (o/w) emulsion to combat mosquitoes has been successfully formulated using palm methyl ester (PME) as carrier solvent, xanthan gum (XG) as thickener and plant-based non-ionic surfactants. The performance of castor oil-based surfactant, polyethylene glycol (20) glyceryl oleoricinoleate (PEG 20G), coupled with palm-based polyoxyethylene (20) sorbitan monooleate (POE 20S) was compared with conventional palm-based surfactant, C12-C14 fatty alcohol ethoxylate (FAE), coupled with POE 20S. The effects of surfactant mixing ratios and total thickener concentrations on stability, droplet size, microstructure and viscosity of the resulting emulsions were investigated. Emulsions obtained with a mixture of the two palm-based surfactants exhibited superior emulsification efficiency and stability in comparison to emulsions obtained with a mixture of castor oil and palm-based surfactant. The results indicated that the molecular structure of palm-based surfactants positively affect surfactant packing conformation at the oil/aqueous phase interface. The present study opens the possibility of using palm-based surfactants in insecticide emulsions in an effort to curb the spread of mosquito-borne diseases around the world.
\end{abstract}

Keywords: palm-based surfactants, insecticide, emulsion, non-ionic surfactants, palm methyl ester.

Date received: 23 July 2018; Sent for revision: 24 July 2018; Received in final form: 7 October 2018; Accepted: 7 October 2019 .

\section{INTRODUCTION}

The rise in mosquito-borne diseases has called for more intensified space spraying treatments using insecticides in order to provide rapid reduction of mosquito population and interrupt disease transmission cycle (Swillen, 2013). Oil-in-water $(\mathrm{o} / \mathrm{w})$ insecticide emulsion presents an attractive option due to its low solvent content per unit active ingredient. It comprises of oil droplets dispersion in a body of water with the assistance of surfactants. Surfactants facilitate mixing of oil and water phase,

\footnotetext{
* Malaysian Palm Oil Board, 6 Persiaran Institusi, Bandar Baru Bangi, 43000 Kajang, Selangor, Malaysia. E-mail: sumaiyah@mpob.gov.my
}

increase emulsion stability and enhance insecticide efficiency by increasing dispersion, improving contact and controlling spray drift (Rust and Wildes, 2008). Compared to oil-based systems, water dilutable $\mathrm{o} / \mathrm{w}$ emulsions have lower volatility, higher flash points and lower skin and eye toxicity (Gasic et al., 2012).

In the present study, o/w insecticide emulsion for mosquito control was developed by using deltamethrin (Figure 1), a mosquito larvicide and adulticide. Popularity of deltamethrin is attributed to its efficacy, persistence, residual activity and low toxicity to mammals. Deltamethrin rapidly paralyses an insect's nervous system to give a quick knockdown effect (Kumar et al., 2011). In comparison to other insecticidal actives, it is less 
<smiles>CC1(C)[C@@H](C=C(Br)Br)[C@H]1C(=O)O[C@H](C#N)c1cccc(Oc2ccccc2)c1</smiles>

Figure 1. Chemical structure of deltamethrin.

harmful to humans due to its chemical stability, non-volatile nature and low inhalation risk (Rehman et al., 2014). Moreover, in vitro and in vivo assays have established the compound to be non-genotoxic (Kavlock et al., 1979; Pluijmen et al., 1984; Poláková and Vargová, 1983). Deltamethrin is typically prepared in petroleum-based solvents due to its poor water solubility (less than $2 \mu \mathrm{g} \mathrm{litre}^{-1}$ at $25^{\circ} \mathrm{C}$ ) (Daka et al., 2006). However, petroleum-based solvents are volatile, have low flash points, and pose high safety risk and fire hazard during handling, storage and application. In the current work, palm methyl ester (PME) was used as the carrier solvent due to its lower volatility and higher flash point in comparison to petroleum-based solvents (Mohsin et al., 2017).

Plant-based surfactants are applied in the present study as they are biodegradable, have minimum health risk to humans and support the need to reduce reliance on non-renewable resources and avoid environmental pollution problems that comes with petroleum production process (Permadi et al., 2017). Additionally, they can be produced from non-edible oils such as Jatropha plant oil (Elrais et al., 2009) and castor seed oil (Huang et al., 2016), thus, abstaining from conflict with food application of renewable resources. Non-ionic surfactants were chosen due to their ease in forming emulsions by both low and high energy methods (McClements and Rao, 2011). Three non-ionic surfactants were utilised: lipophilic polyethylene glycol (20) glyceryl oleoricinoleate (PEG 20G), lipophilic C12-C14 fatty alcohol ethoxylate (FAE) and hydrophilic polyoxyethylene (20) sorbitan monooleate (POE 20S).

Castor oil-based novel surfactant PEG 20G is non-irritant, does not carry a risk phrase and has good toxicological and ecological properties. FAE and POE $20 \mathrm{~S}$ are conventional surfactants from palm origin (Mezzanotte et al., 2002; Franzetti et al., 2006). Palm-based surfactants are known to be readily biodegradable (Rakmi et al., 1997; Ghazali and Ahmad, 2004; Afida et al., 2016) and have exhibited promising results when applied in pesticidal applications. Palm-based FAE (Ismail et al., 2014) and diethanolamide (Nisya et al., 2017) were found to improve spreading and wetting of herbicide and insecticide emulsion, respectively. The earlier surfactant contributed to higher biological efficacy on a broad range of weed species while the later was instrumental in inducing high mortality of Spodoptera litura larvae.

Hydrophilic-lipophilic balance (HLB) method is widely used for guiding surfactant selection for emulsions and estimating the hydrophiliclipophilic characteristic of surfactants and oils due to its convenience, simplicity and easy-to-use formula. However, the method has demonstrated poor accuracy in predicting relative efficiency and effectiveness as the method only takes into account relative contribution of hydrophilic and hydrophobic fragments of surfactants (Witthayapanyanon et al., 2008). The method does not take into account the impact of other variables such as surfactant structure and interactions between thickener and surfactants. Therefore, in the current work, we attempt to further review the influence of surfactant structure and its interaction with thickener on the stability and physico-chemical properties of emulsions.

\section{MATERIALS AND METHODS}

\section{Materials}

PME: methyl caproate/octanoate/decanoate/ laurate $(3.2 / 50.8 / 44.0 / 2.0 \mathrm{wt} \%)$ was supplied by Cognis Oleochemicals (M) Sdn Bhd. Deltamethrin (98.0\%) was provided by Hextar Chemicals (Malaysia) Sdn Bhd. Xanthan gum (XG) from Xanthomonas campestris was purchased from SigmaAldrich (M) Sdn Bhd. Distilled water was used in all experiments. Polyethylene glycol (20) glyceryl oleoricinoleate (PEG 20G) produced by Evonik Industries (Germany) was kindly donated by Oriental Techno Chemicals Sdn Bhd. Polyoxyethylene (20) sorbitan monooleate (POE 20S) was purchased from Huntsman Singapore Pte Ltd while C12-C14 FAE was purchased from Chemweb Sdn Bhd. Properties of utilised surfactants are summarised in Table 1.

\section{Emulsion Preparation}

The emulsions were formed using $2 \mathrm{wt} \%$ deltamethrin, $5 \mathrm{wt} \%$ mixture of surfactants and 13 wt $\%$ PME as the oil phase and distilled water as the aqueous phase. First, the oil phase was stirred for $10 \mathrm{~min}$ at $55^{\circ} \mathrm{C}$ using a magnetic stirrer. Then, the emulsions were obtained by progressively incorporating the oil phase into the aqueous phase using a rotor-stator homogeniser model Polytron ${ }^{\circledR}$ PT3100 (New York, USA) at speeds up to 7000 $\mathrm{rpm}$ for $10 \mathrm{~min}$. The resulting emulsions were 
TABLE 1. PROPERTIES OF NON-IONIC SURFACTANTS

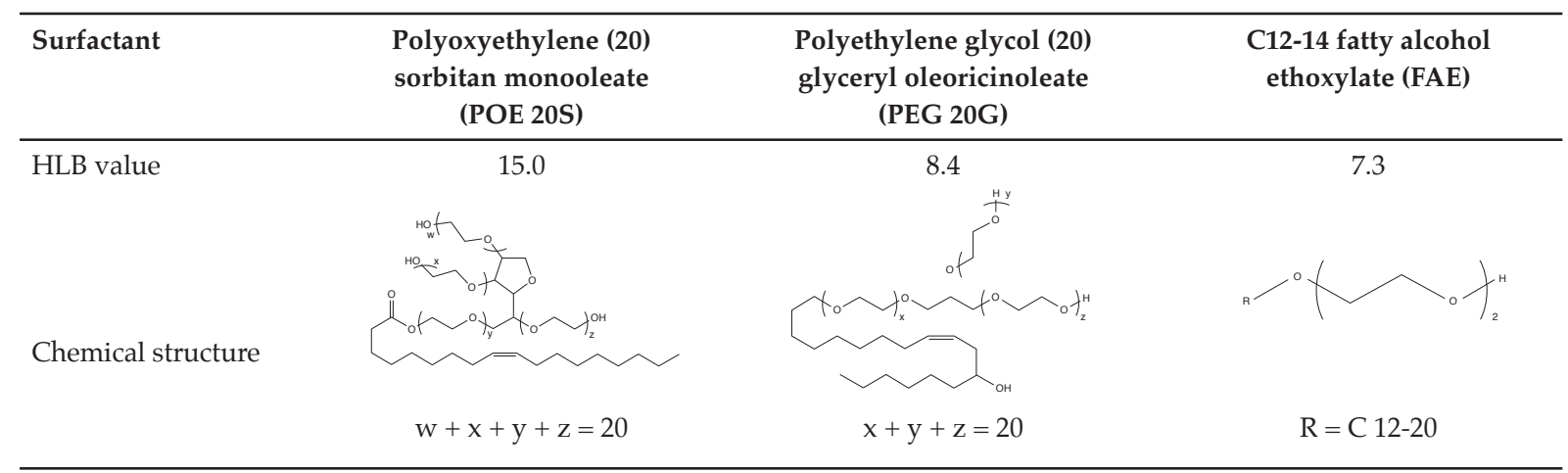

Note: HLB - hydrophilic-lipophilic balance.

then cooled to room temperature. For thickener incorporated emulsions, the aqueous phase was prepared prior to homogenisation by dispersing XG in distilled water at $55^{\circ} \mathrm{C}$. Emulsions prepared with POE 20S and PEG 20G will henceforth be referred to as TB emulsions. Emulsions stabilised with POE 20S and FAE, hereinafter referred to as TD emulsions, were produced as benchmark for comparing the performance of PEG 20G. The combinations of lipophilic and hydrophilic surfactants are known to facilitate formation of small droplets irrespective of emulsification method (McClements and Rao, 2011). The required HLB value for PME was determined by changing the proportion of PEG 20G and FAE to POE 20S. The HLB of non-ionic surfactant mixture was calculated according to equation below (Jiang et al., 2012):

$$
\mathrm{HLB}_{\text {mix }}=\frac{\mathrm{wt} \% \text { of surfactant } \mathrm{A}}{100} \times\left(\mathrm{HLB}_{\mathrm{A}}-\mathrm{HLB}_{\mathrm{B}}\right)+\mathrm{HLB}_{\mathrm{B}}
$$

\section{Stability of Emulsion}

Formulation stability tests were conducted by storing the samples at room temperature for 90 days. Additionally, stability of emulsions at elevated temperature was investigated at $45 \pm 2{ }^{\circ} \mathrm{C}$ for 60 days (WHO, 2010). At ageing Day 1, 7, 14, 30, 45, 60, 75 and 90, visual observations were performed under polarised light in order to detect phase separation.

\section{Characterisation of Emulsion Formulation}

Particle size measurements were conducted in triplicates on Malvern Mastersizer 3000 (Worcestershire, United Kingdom) and reported as averaged volume median (Dv 50). Longterm stability of the emulsions were evaluated by measuring Dv 50 at aforementioned ageing day intervals. Microstructure of the emulsions were observed after 90 days of storage at room temperature under Olympus BX53 microscope (Tokyo, Japan). XG incorporated samples were diluted prior to observation while samples without
XG were observed without dilution. Viscosity at ageing Day 1 were measured at room temperature at a constant shear rate of $100 \mathrm{~s}^{-1}$ using Anton Paar Physica MCR 300 model (Graz, Austria) and the results are presented as mean values.

\section{RESULTS AND DISCUSSION}

The physico-chemical characteristics of emulsions prepared at various HLB values are summarised in Table 2. Appearance of TB and TD emulsions prepared at various HLB values after stability test at $45^{\circ} \mathrm{C}$ for 60 days are shown in Figures $2 a$ and $2 b$, respectively. Emulsions obtained are optically opaque, indicative of macro-emulsion system with droplet sizes of similar dimension to the wavelength of light (Bai and McClements, 2016). Accelerated thermostability test increases the rate of chemical degradation and physical change of the emulsion and provides information on the shelf-life of the emulsion in a relatively short time. Accelerated storage condition recommended by Food and Agriculture Organisation of United Nations (FAO) and World Health Organisation (WHO) specifications for pesticides is six weeks at $45 \pm$ $2{ }^{\circ} \mathrm{C}$ (WHO, 2010). However, even at the excess of 60 days storage, all emulsions showed no apparent flocculation or creaming, with the exception of TD emulsions prepared at HLB 9. Thus, the required HLB value for PME oil phase could not be effectively identified from visual observation.

Thereon, particle size of the emulsions were examined. Dv 50 of deltamethrin macro-emulsions with respect to HLB values and ageing time is shown in Figure 3. Although macro-emulsions are known to be thermodynamically unstable, droplet sizes of the emulsions remain largely unchanged after storage. TD emulsions prepared at HLB 9, 11, 12, 13 and 14 exhibited large particles and thus have a higher tendency for phase separation. In particular, TD emulsion prepared at HLB 9 showed fluctuation in droplet size attributed to insufficient coverage by hydrophilic surfactant molecules. TD emulsion 
TABLE 2. PHYSICO-CHEMICAL CHARACTERISTICS OF INSECTICIDE EMULSIONS PREPARED WITH DIFFERENT SURFACTANT RATIOS AFTER ONE DAY OF STORAGE

\begin{tabular}{|c|c|c|c|c|}
\hline Emulsion & HLB & $\begin{array}{l}\text { Ratio of hydrophilic to } \\
\text { lipophilic surfactant }\end{array}$ & $\begin{array}{l}\text { Volume median, Dv } 50(\mu \mathrm{m}) \\
( \pm \mathrm{SD})\end{array}$ & $\begin{array}{c}\text { Average viscosity (mPa.s) } \\
( \pm \mathrm{SD})\end{array}$ \\
\hline \multirow[t]{3}{*}{ TB } & 9 & $0.45: 4.55$ & $2.03 \pm 0.02$ & $1.35 \pm 0.05$ \\
\hline & 11 & $1.97: 3.03$ & $1.95 \pm 0.00$ & $1.37 \pm 0.05$ \\
\hline & 12 & $2.73: 2.27$ & $2.07 \pm 0.02$ & $1.29 \pm 0.05$ \\
\hline \multirow[t]{4}{*}{$\mathrm{TD}$} & 9 & 1.1:3.9 & $1.84 \pm 0.01$ & $1.32 \pm 0.05$ \\
\hline & 10 & $1.75: 3.25$ & $1.41 \pm 0.01$ & $1.43 \pm 0.05$ \\
\hline & 11 & $2.4: 2.6$ & $1.55 \pm 0.01$ & $1.32 \pm 0.05$ \\
\hline & 12 & 3.05:1.95 & $1.74 \pm 0.01$ & $1.13 \pm 0.05$ \\
\hline
\end{tabular}

Note: HLB - hydrophilic-lipophilic balance.

(a)

(b)
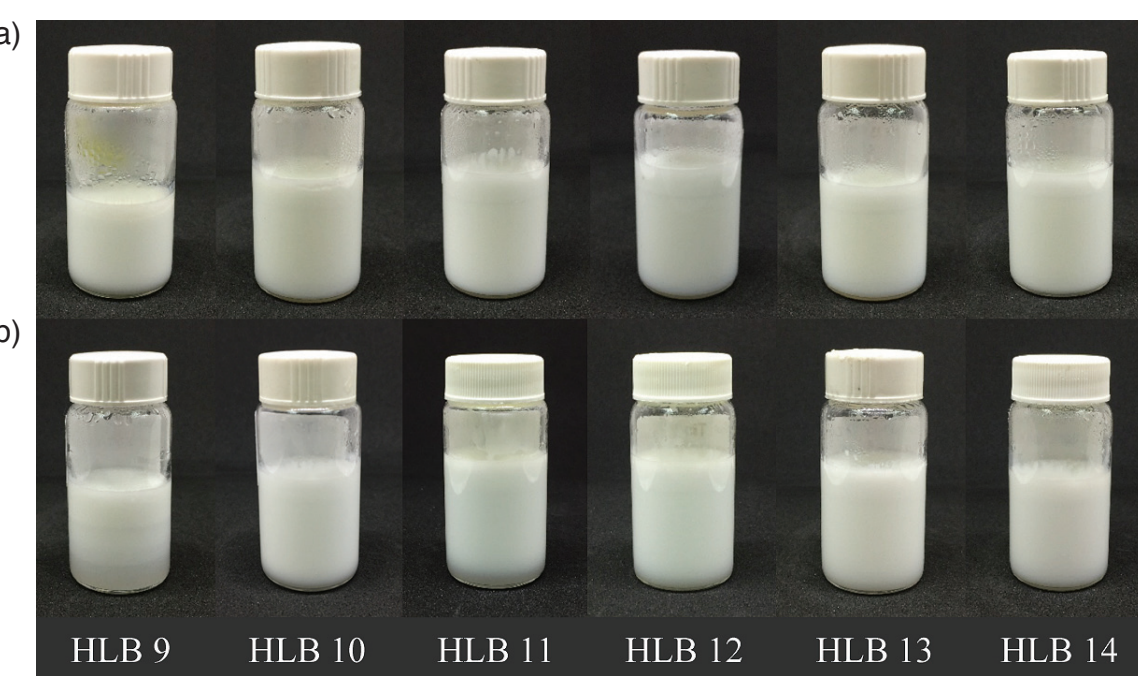

Figure 2. Appearance of TB (a) and TD (b) emulsions after stability test at $45^{\circ} \mathrm{C}$ for 60 days.

prepared at HLB 10 exhibited the lowest Dv 50 value due to high emulsification efficiency. Hence, the required HLB for PME can be concluded as 10. This slightly hydrophilic value relates to the moderately polar nature of the main components of PME, namely, methyl octanoate and methyl decanoate. In the current study, predominantly short-chained PME were used in order to dissolve the moderately polar deltamethrin. For TB emulsions, the proportion of hydrophilic to lipophilic surfactant was observed to have very little impact on droplet size as only slight droplet size difference was observed. In general, emulsions obtained with PEG 20G and POE 20S exhibit larger droplet size in comparison to emulsions obtained with FAE and POE 20S. Such observation is also supported by microscopic images of TB and TD emulsions presented in Figure 4.

Next, the effect of HLB values on average viscosity of TB and TD emulsions was investigated and is presented in Figure 5. Consistent with particle size analysis results, marginal difference in average viscosity was observed for TB emulsions prepared at HLB 9 to 13. Marked increase in viscosity for TB emulsion prepared at HLB 14 is more likely related to a depletion flocculation process due to an excess of surfactant micelles rather than viscosity of the continuous phase (Pérez-Mosqueda et al., 2014). On the other hand, TD emulsion prepared at HLB 10 displayed the highest average viscosity. Taking into account its stability to creaming or sedimentation and low droplet size, it can thus be postulated that this high viscosity is attributed to increased oil droplet concentration (Bai and McClements, 2016).

Interface packing conformations of surfactants have a direct impact on the average droplet size, emulsification efficiency and interfacial properties of emulsions (Casanova et al., 2005). At the wateroil interface, hydrophilic and lipophilic surfactants align side by side in order to provide greater rigidity and strength to the interfacial film (Du et al., 

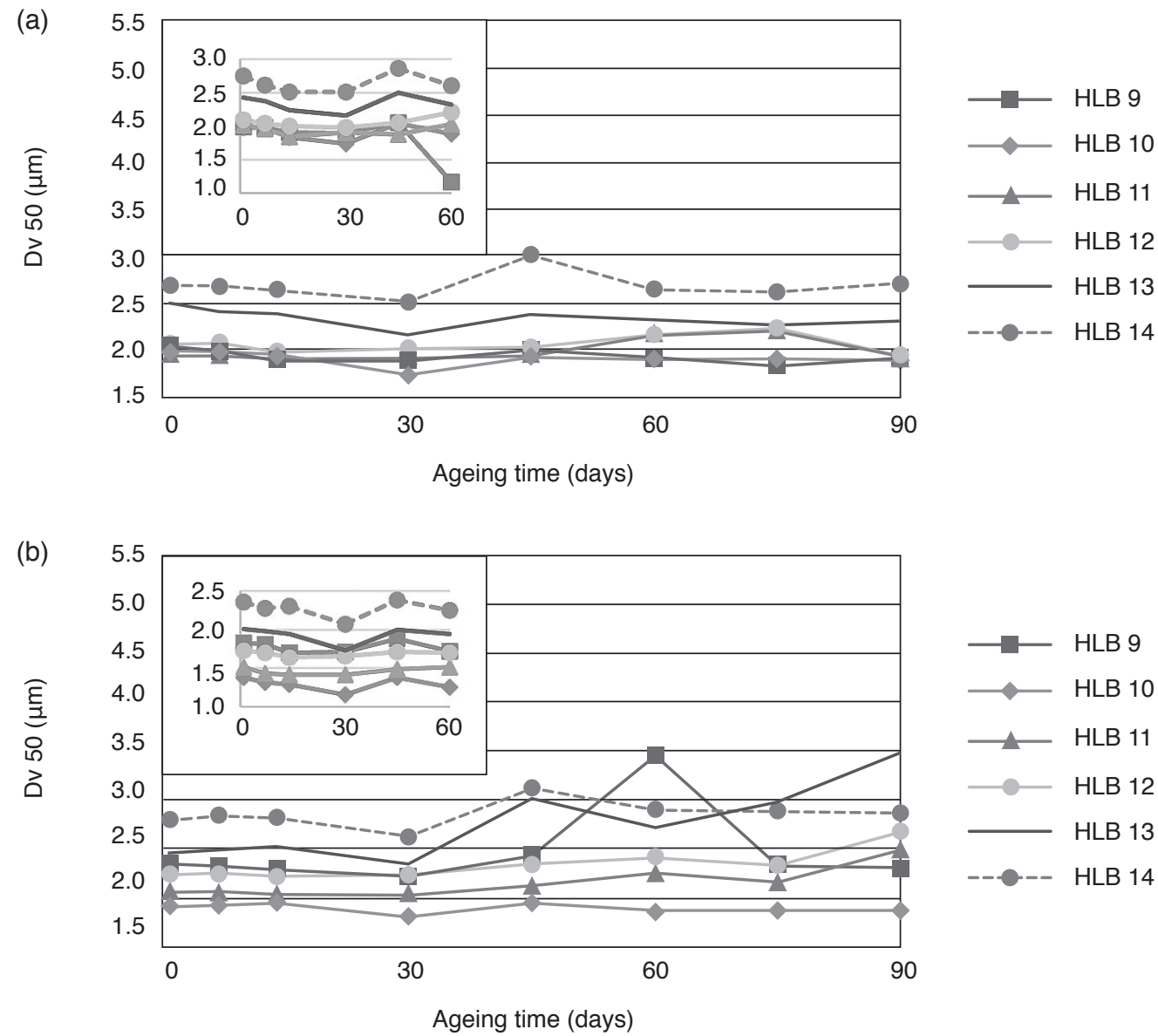

Figure 3. Particle size of TB (a) and TD (b) emulsions studied as a function of ageing time and hydrophilic-lipophilic balance (HLB) value. The emulsions were stored at room temperature (outset) and $45^{\circ} \mathrm{C}$ (inset).

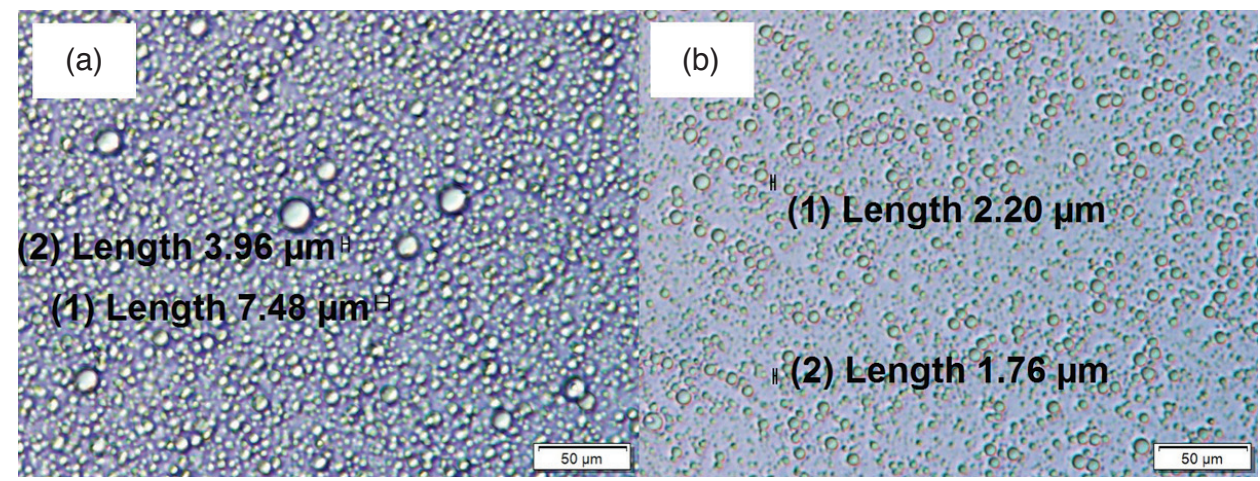

Figure 4. Microscopic images of TB (a) and TD (b) emulsions prepared at HLB 11 at $20 X$ magnification. The images were taken after 90 days of storage at room temperature.

2016). Due to these allocations, there is a restricted number of packing conformations that could take place in order to produce a well-packed interface with minimum interface free energy. In order to obtain optimum packing beneficial for emulsion stability, surfactants should have a geometry such as the size of the lipophilic head matches that of the hydrophobic tail. It can be seen from Table 1 that both POE $20 S$ and FAE observe this condition. POE 20S comprises bulky polyoxyethylene head group and a long unsaturated oleic acid tail group while FAE is made of small alcohol ethoxylate head group and short alkyl tail group. Critical packing parameters are determined by optimum surface area of the head groups $\left(a_{\mathrm{o}}\right)$, effective hydrocarbon volume $(V)$ and critical chain length $l_{c}$. The $a_{\mathrm{o}}$ is determined by the repulsive hydrophilic forces acting between the head groups which are balanced by the attractive hydrophobic forces acting at the hydrocarbon water interface. The $V$ and $l_{c}$ are influenced by the 


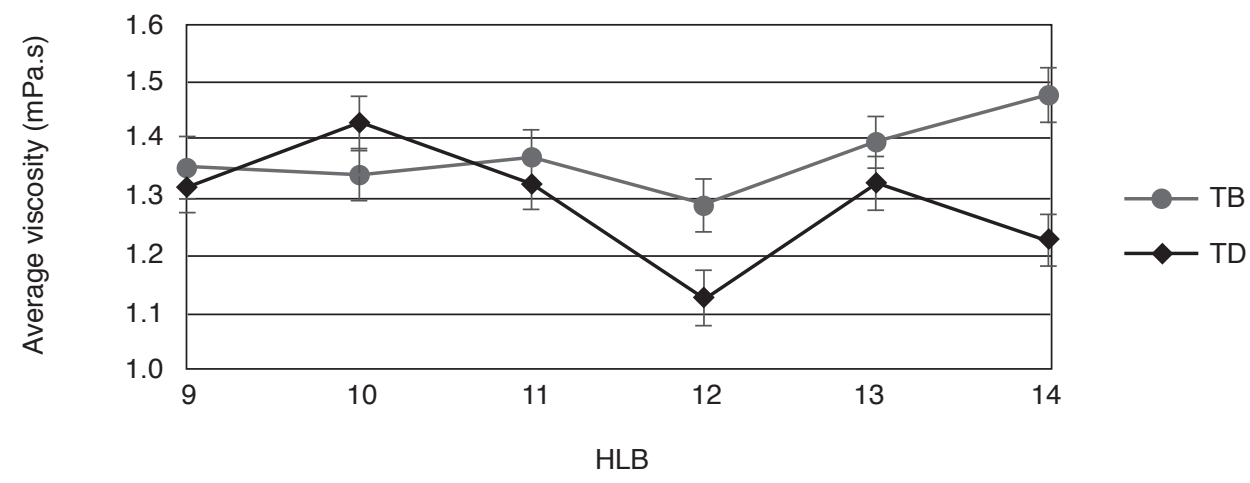

Figure 5. Average viscosity of emulsions prepared at various hyrodphilic-lipophilic balance (HLB) values.

steric chain-chain and oil-penetration interaction within the hydrocarbon interior of the surfactant (Israelachvili, 1994). Surfactants with a balanced hydrophilic head group and length of lipophilic alkyl chain like POE $20 S$ and FAE tend to observe lamellar aggregation with the surfactant sitting perpendicularly to the water-oil interface. Alternating arrangement of the bulky and small surfactant structure facilitates surfactant synergism and allows close packing with hydrophilic head and lipophilic tail of both surfactants binding well into both regions of the emulsion, as illustrated in Figure $6 b$. Thus, smaller average droplet size and higher emulsification efficiency were obtained with POE $20 S$ and FAE.

Separately, PEG 20G comprises a polyethylene glycol head group and a hydroxyl group anomaly on its long chain unsaturated oleic acid tail group (Table 1). Although the tail of PEG 20G is similar to POE 20S, the hydroxyl group at the centre of the tail group resulted in weak lipophilicity and less than proportionate binding sites for different regions of $\mathrm{o} / \mathrm{w}$ emulsions. We hypothesise that the lipophilic tail of PEG 20G is forced to align along the surface of oil droplet while the hydrophilic hydroxyl group and polyoxyethylene group reside in the aqueous phase. As a result, $l_{c}$ is reduced and $V$ is increased while $a_{\mathrm{o}}$ remain unchanged from POE 20S. Participating surfactants are then positioned away from each other, changing from a relatively packed interface obtained in TD emulsions to loosely packed interface in TB emulsions. Hypothetical conformations of TB emulsions is illustrated in Figure 6a. Consequently, larger droplets with weaker colloidal barrier were formed, making the emulsion more prone to droplet aggregation. The comparatively larger droplet size for TB emulsions as reported in Table 2 confirms the effect of this interface packing conformation.

In order to further increase the stability of emulsions, XG was introduced into the emulsions. High-molecular weight polysaccharides have the ability to prevent creaming or sedimentation by increasing the viscosity of emulsions (Sun et al.,
2007). The effect of XG concentration on emulsion stability, droplet size and rheology is investigated at HLB 10. Photographs of XG incorporated TB and TD emulsions after stability test at $45^{\circ} \mathrm{C}$ for 60 days are shown in Figures $7 a$ and $7 b$, respectively. The physico-chemical characteristics of resulting emulsions are summarised in Table 3. XG addition produced viscous opaque emulsions that remain stable as a single phase until up to 90 days of storage at room temperature (not pictured). However, it was observed that TB emulsions are less stable at elevated temperature in comparison to TD emulsions, showing phase separation even with XG concentration as high as $0.5 \mathrm{wt} \%$. Poor stability of TB emulsions can be attributed to the unfavourable interface packing conformation by PEG 20G in the oil phase, as discussed above. Separation occurred in the form of an apparent creaming at the top and a translucent phase at the bottom, a phenomenon typically observed in emulsions containing XG (Zhang and Liu, 2011). Such observation is attributed to depletion flocculation induced by XG. As a polyelectrolyte, XG do not absorb at the interfaces of oil and aqueous phase, but rather induce electrostatic repulsion to inhibit oil droplet coalescence. At the region of close separation between the oil droplets, negatively charged XG molecules are squeezed out due to repulsion from similarly negatively charged oil droplets. As the concentration of XG is reduced, an osmotic pressure is formed, prompting solvent at the region of close separation to flow out (Tadros, 2013). The consequence of this phenomenon was observed as XG-rich emulsion phase at the top and XG-depleted serum phase at the bottom.

Droplet size evolution of TB and TD emulsions prepared at various concentrations of $X G$ are shown in Figures $8 a$ and $8 b$, respectively. Typically, droplet sizes of XG incorporated emulsions remain relatively unchanged with storage time due to the non-absorbing nature of the polysaccharide. The presence of XG induces weak depletion flocculation that is reversible upon dilution to disintegrate into single droplets during droplet size measurements 
(a)
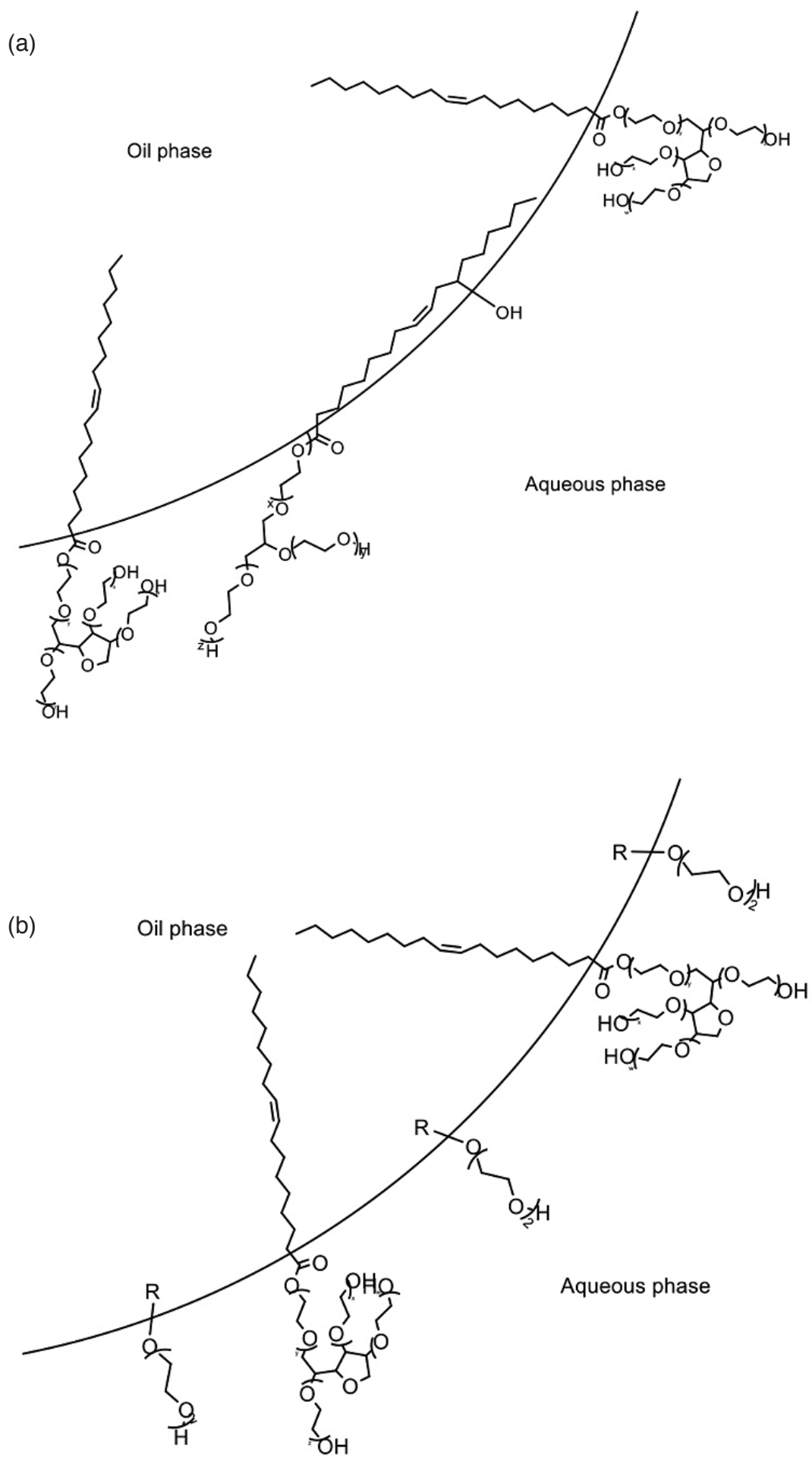

Figure 6. Schematic of oil droplets in TB (a) and TD (b) emulsion, showing the hypothetical orientation of non-ionic surfactants at the interface.

(Sun et al., 2007; Moschakis et al., 2005; Ye et al., 2004). Such is true with TD emulsions as no significant changes in droplet size was observed after storage at elevated temperature despite the apparent creaming of TD emulsion with $0.3 \mathrm{wt} \%$ XG. However, the same could not be said with $\mathrm{TB}$ emulsions stored at $45^{\circ} \mathrm{C}$ as substantial increase of droplet sizes were observed with ageing time. TB emulsions possess a weaker colloidal barrier as a result of unfavourable interface packing conformation. As XG induced depletion flocculation persist, osmotic interaction and van der Waals become great enough to overcome steric stabilisation by non-ionic surfactants and the oil droplets come in close contact in a floc. Eventually, the surfactant film rupture, resulting in coalescence into bigger droplets as evident by the increase of 
TABLE 3. PHYSICO-CHEMICAL CHARACTERISTICS OF INSECTICIDE EMULSIONS PREPARED WITH DIFFERENT XG RATIOS AFTER ONE DAY OF STORAGE

\begin{tabular}{cccc}
\hline $\begin{array}{c}\text { Emulsion } \\
\text { HLB 10 }\end{array}$ & $\begin{array}{c}\text { Concentration of XG } \\
(\mathbf{w t} \%)\end{array}$ & $\begin{array}{c}\text { Volume median, Dv } \mathbf{5 0} \\
(\boldsymbol{\mu} \mathbf{m})( \pm \mathrm{SD})\end{array}$ & $\begin{array}{c}\text { Average viscosity }(\mathbf{m P a}) \mathbf{s}) \\
( \pm \mathrm{SD})\end{array}$ \\
\hline TB & 0 & $1.99 \pm 0.02$ & $1.34 \pm 0.04$ \\
& 0.3 & $1.45 \pm 0.01$ & $42.0 \pm 0.1$ \\
& 0.4 & $1.33 \pm 0.01$ & $57.8 \pm 0.2$ \\
TD & 0.5 & $1.50 \pm 0.01$ & $76.3 \pm 0.4$ \\
& 0 & $1.41 \pm 0.01$ & $1.43 \pm 0.05$ \\
& 0.3 & $1.64 \pm 0.01$ & $44.4 \pm 0.1$ \\
& 0.4 & $1.48 \pm 0.01$ & $62.4 \pm 0.1$ \\
& 0.5 & $1.44 \pm 0.01$ & $82.9 \pm 0.3$ \\
\hline
\end{tabular}

Note: HLB - hydrophilic-lipophilic balance.

(a)

(b)

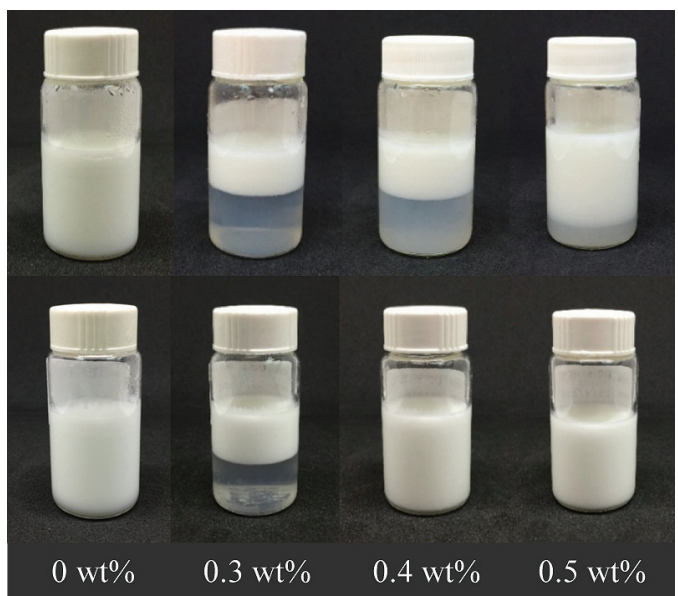

Figure 7. Appearance of XG incorporated TB (a) and TD (b) emulsions after stability test at $45^{\circ} \mathrm{C}$ for 60 days.
Dv 50 with ageing time (Figure 8b). Microscopic observations of emulsions after ageing showed a broader droplet size distribution for TB emulsion compared to TD emulsion due to coalescence (Figure 9). Further, TB emulsion droplets are non-spherical and largely deformed due to the destabilisation of the emulsion.

Average viscosity of XG incorporated emulsions increases linearly with increasing XG concentration, as shown in Figure 10. Notably, phase separation occurred at a slower rate in TB emulsions with higher XG concentration due to immobilisation of dispersed oil droplets in a weak gel-like network. No phase separation was observed in TD emulsions prepared with 0.4 and $0.5 \mathrm{wt} \%$ of XG. At constant $X G$ concentration, the differences in viscosity
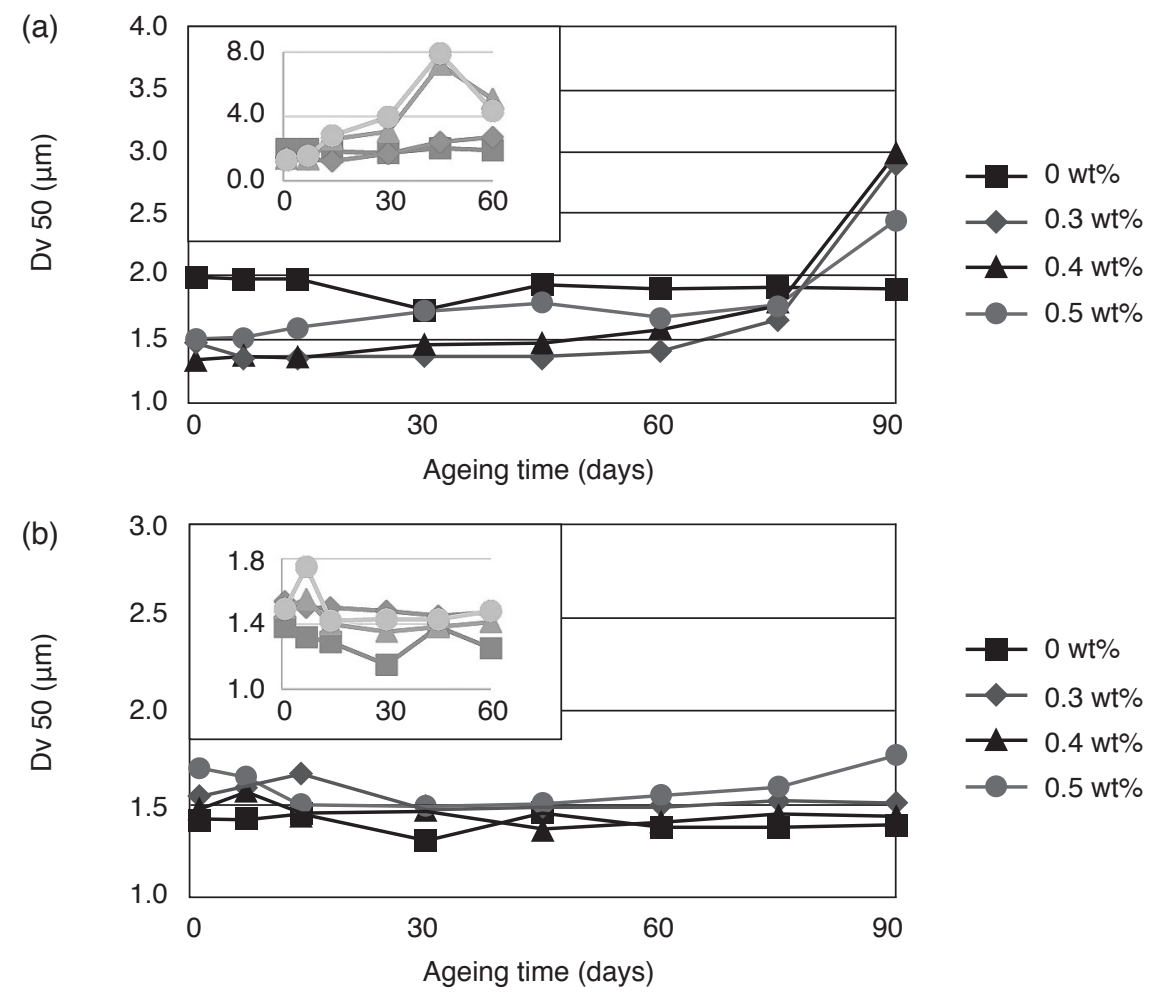

Figure 8. Particle size of TB (a) and TD (b) emulsions studied as a function of ageing time and XG concentration. The emulsions were stored at room temperature (outset) and $45^{\circ} \mathrm{C}$ (inset). 


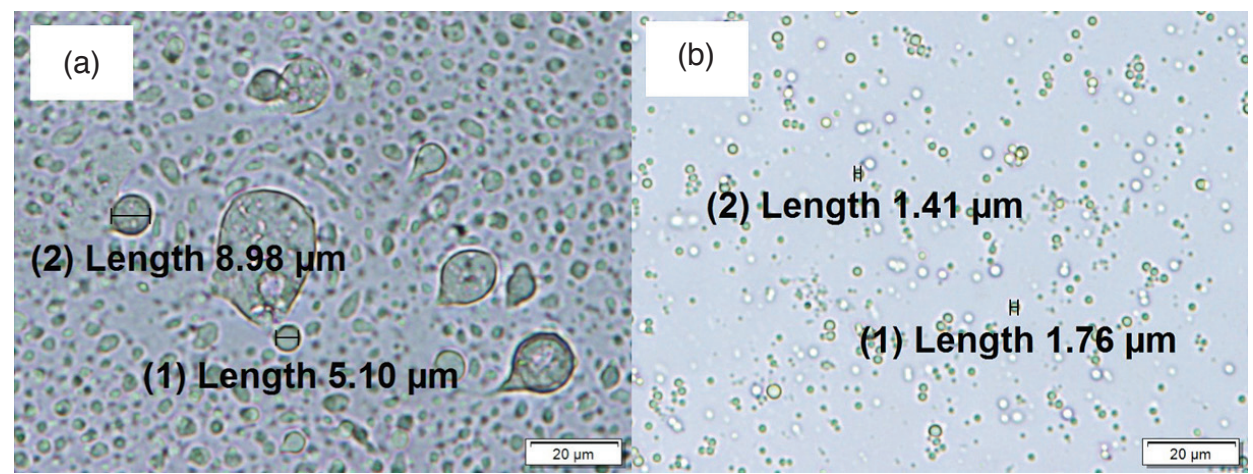

Figure 9. Microscopic images of 0.5 wt\% XG incorporated TB (a) and TD (b) emulsions at $50 X$ magnification. The images were taken after 90 days of storage at room temperature.

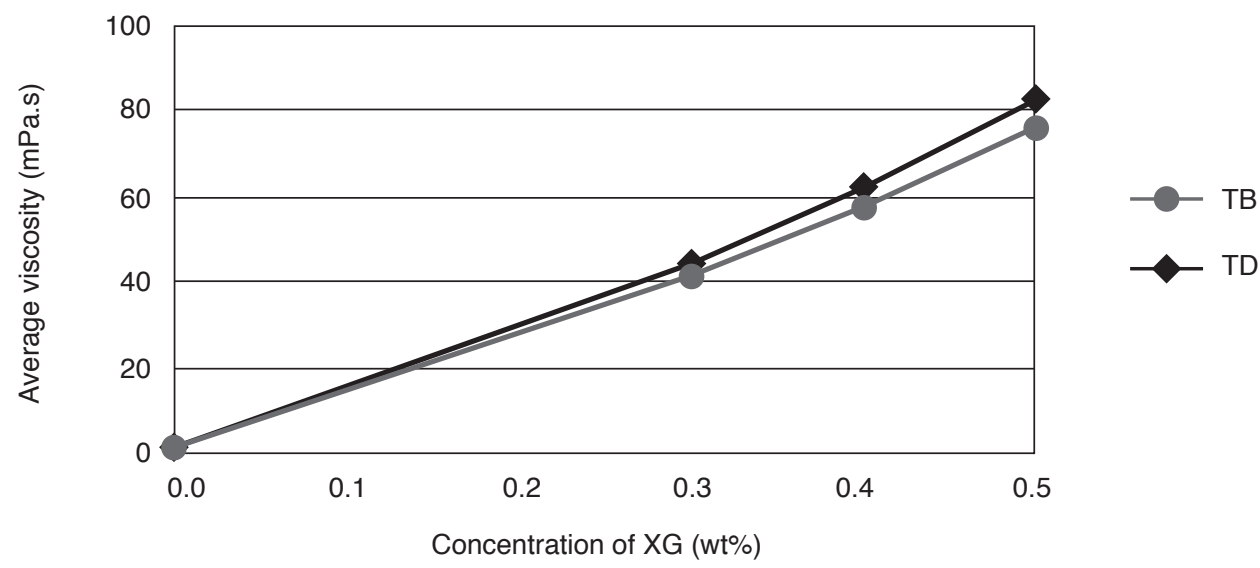

Figure 10. Average viscosity of emulsions prepared at various concentrations of xanthan gum (XG).

are small in magnitude with TD emulsion being slightly more viscous. Regardless, destabilisation was more prominent in TB emulsions due to the aforementioned interface packing conformation.

\section{CONCLUSION}

Stable o/w insecticide emulsions were successfully formulated using insecticide deltamethrin as the active ingredient, PME as the carrier solvent, $X G$ as the thickener and a mixture of non-ionic surfactants. The required HLB value for the oil phase was determined to be 10 according to stability of emulsions in terms of minimum droplet size and viscosity. The use of castor oil-based surfactant, PEG $20 \mathrm{G}$ in combination with palm-based surfactant POE $20 S$ was compared with combination of two palm-based surfactants, FAE and POE 20S. The study suggests that the emulsification efficiency of the emulsions is likely governed by interface packing conformation of the surfactant mixture. Emulsions obtained with PEG 20G and POE 20S produced comparatively larger oil droplets and less stable emulsions due to loosely packed interface conformation. In an attempt to increase viscosity and stability, XG was added. However, XG in TB emulsions further expedited depletion flocculation and coalescence of oil droplets during accelerated thermostability testing. With POE $20 S$ and FAE, it was possible to obtain stable emulsions at XG concentrations of $0.4 \mathrm{wt} \%$ and above.

\section{ACKNOWLEDGEMENT}

The authors wish to thank the Director-General of MPOB for permission to publish this article. Additionally, we thank Evonik Industries (Germany) and Hextar Chemicals (Malaysia) for their guidance and supply of PEG 20G surfactant and deltamethrin, respectively.

\section{REFERENCES}

Afida, S; Razmah, G and Zulina, A M (2016). Biodegradation of various homologues of palmbased methyl ester sulphonates (MES). Sains Malaysiana, 45(6): 949-954.

Bai, L and Mcclements, D J (2016). Extending emulsion functionality: Post-homogenization modification of droplet properties. Processes, 4(17): 1-18. 
Casanova, H; Araque, P and Ortiz, C (2005). Nicotine carboxylate insecticide emulsions: Effect of the fatty acid chain length. J. Agric. Food Chem., 53(26): 99499953.

Daka, P S; Obuseng, V C; Torto, N and HuntsmanMapila, P (2006). Deltamethrin in sediment samples of the Okavango Delta, Botswana. Water Sa., 32(4): 483-488.

Du, Z; Wang, C; Tai, X; Wang, G and Liu, X (2016). Optimization and characterization of biocompatible oil-in-water nanoemulsion for pesticide delivery. ACS Sustainable Chem. Eng., 4(3): 983-991.

Elraies, K A; Isa, M T and Saaid, I (2009). Synthesis and performance of a new surfactant for enhanced oil recovery. Int. J. Pet. Sci. Technol., 3(1): 1-9.

Franzetti, A; Di Gennaro, P; Bevilacqua, A; Papacchini, M and Bestetti, G (2006). Environmental features of two commercial surfactants widely used in soil remediation. Chemosphere, 62(9): 1474-1480.

Gašić, S; Brkić, D; Radivojević, L and Tomašević, A (2012). Development of water based pesticide system. Pestic. Phytomed., 27(1): 77-81.

Ghazali, R and Ahmad, S (2004). Biodegradability and ecotoxicity of palm stearin-based methyl ester sulphonates. J. Oil Palm Res. Vol. 16(1): 39-44.

Huang, X; Liu, H; Shang, S; Cai, Z; Song, J and Song, $Z$ (2016). Synthesis and characterization of castor oil-based polymeric surfactants. Front. Agr. Sci. Eng., 3(1): 46-54.

Ismail, A R; Nor Farhana, N; Mahiran, B; Dzolkhifli, $\mathrm{O}$ and Hazimah, A H (2014). Oil-in-water emulsion (EW) of mixed glyphosate isopropylamine (IPA) and triclopyr butoxyethylester (BEE) stabilised by palm-based emulsifiers for weed control. J. Oil Palm Res. Vol. 26(4): 366-374.

Israelachvili, J (1994). The science and applications of emulsions - An overview. Colloids Surf. A. Physicochem. Eng. Asp., 91: 1-8.

Jiang, L C; Basri, M; Omar, D; Rahman, M B A; Salleh, A B; Rahman, R N Z R A and Selamat, A (2012). Green nano-emulsion intervention for water-soluble glyphosate isopropylamine (IPA) formulations in controlling Eleusine indica (E. indica). Pest. Biochem. Physiol., 102(1): 19-29.

Kavlock, R; Chernoff, N; Baron, R; Linder, R; Rogers, E; Carver, B; Dilley, J and Simmon, V (1979). Toxicity studies with decamethrin, a synthetic pyrethroid insecticide. J. Environ. Pathol. Toxicol., 2(3): 751-765.
Kumar, S; Thomas, A and Pillai, M K K (2011). Deltamethrin: Promising mosquito control agent against adult stage of Aedes aegypti L. Asian Pac. J. Trop. Med., 4(6): 430-435.

Mcclements, D J and Rao, J (2011). Food-grade nanoemulsions: Formulation, fabrication, properties, performance, biological fate, and potential toxicity. Crit. Rev. Food Sci. Nutr., 51(4): 285-330.

Mezzanotte, V; Bolzacchini, E; Orlandi, M; Rozzi, $A$ and Rullo, S (2002). Anaerobic removal of linear alcohol ethoxylates. Bioresour. Technol., 82(2): 151156.

Mohsin, S M N; Raman, I A; Hasan, ZAA and Idris, Z (2017). Palm-based methyl esters as carrier solvents in pesticide formulations. Palm Oil Developments No. 66: 8-14

Moschakis, T; Murray, B S and Dickinson, E (2005). Microstructural evolution of viscoelastic emulsions stabilised by sodium caseinate and xanthan gum. J. Colloid Interface Sci., 284(2): 714-728.

Nisya, F N; Prijono, D and Nurkania, A (2017). Application of diethanolamide surfactant derived from palm oil to improve the performance of biopesticide from neem oil. IOP Conf. Ser.: Earth Environ. Sci., 65(1): 1-10.

Pérez-Mosqueda, L M; Ramírez, P; Trujillo-Cayado, L A; Santos, J and Muňoz, J (2014). Development of eco-friendly submicron emulsions stabilized by a bio-derived gum. Colloids Surf. B Biointerfaces, 123: 797-802.

Permadi, P; Fitria, R and Hambali, E (2017). Palm oil based surfactant products for petroleum industry. IOP Conf. Ser.: Earth Environ. Sci., 65(1): 1-6.

Pluijmen, M; Drevon, C; Montesano, R; Malaveille, C; Hautefeuille, A and Bartsch, H (1984). Lack of mutagenicity of synthetic pyrethroids in Salmonella typhimurium strains and in V79 Chinese hamster cells. Mutat. Res., 137(1): 7-15.

Poláková, H and Vargová, M (1983). Evaluation of the mutagenic effects of decamethrin: Cytogenetic analysis of bone marrow. Mutat. Res., 120(2-3): 167171.

Rakmi, A R; Othman, O and Tjahhono, H (1997). Preparation of biodegradable and vegetable based surfactant from sugar and palm fatty acid catalysed by Mucor miehei lipase. Elaeis, 9(2): 100-110.

Rehman, H; Aziz, A T; Saggu, S; Abbas, Z K; Mohan, A and Ansari, A A (2014). Systematic review 
on pyrethroid toxicity with special reference to deltamethrin. J. Entomol. Zool. Stud., 2(6): 60-70.

Rust, D and Wildes, S (2008). Surfactants - A market opportunity study update. http: / / soynewuses.org / wp-content / uploads / MOS_Surfactants2009.pdf, accessed on 13 February 2018.

Sun, C; Gunasekaran, S and Richards, M P (2007). Effect of xanthan gum on physicochemical properties of whey protein isolate stabilized oil-inwater emulsions. Food Hydrocoll., 21(4): 555-564.

Swillen, L (2013). The use of fog generators in integrated vector control: Thermal fog and cold fog (ULV) generators. http:/ / www.asiansvemc. org / wp-content / uploads / 2014 / 10 / 001-LUCFog-Generator-Manual_140327.pdf, accessed on 7 October 2018.

Tadros, T F (2013). Emulsion Formation and Stability (Tadros, T F ed.). Wiley-VCH Verlag $\mathrm{GmbH}$ \&
Co. KGaA, Weinheim, Germany. p. 75. DOI: 10.1002/9783527647941.ch1.

Witthayapanyanon, A; Harwell, J H and Sabatini, D A (2008). Hydrophilic-lipophilic deviation (HLD) method for characterizing conventional and extended surfactants. J. Colloid Interface Sci., 325(1): 259-266.

WHO (2010). Manual on development and use of $\mathrm{FAO}$ and $\mathrm{WHO}$ specifications for pesticides. http: / / www.fao.org/3/a-i5713e.pdf, accessed on 13 February 2018.

Ye, A; Hemar, Y and Singh, H (2004). Enhancement of coalescence by xanthan addition to oil-in-water emulsions formed with extensively hydrolysed whey proteins. Food Hydrocoll., 18: 737-746.

Zhang, X and Liu, J (2011). Effect of Arabic gum and xanthan gum on the stability of pesticide in water emulsion. J. Agric. Food Chem., 59: 1308-1315. 